\title{
Wild-Type P53 Induces Sodium/ Iodide Symporter Expression Allowing Radioiodide Therapy in Anaplastic Thyroid Cancer
}

\author{
Lin Liu ${ }^{a, b}$ Dan Lia Zhengqi Chen ${ }^{c}$ Jian Yang ${ }^{d}$ Yushui Ma ${ }^{a}$ Haidong Caia \\ Chengxiang Shan ${ }^{\mathrm{e}}$ Zhongwei Lva $\quad$ Xiaoping Zhang ${ }^{\mathrm{a}, \mathrm{b}}$ \\ aDepartment of Nuclear Medicine, Shanghai Tenth People's Hospital, Tongji University, Shanghai, \\ bDepartment of Institution of Interventional and Vascular Surgery, Tongji University, Shanghai, \\ 'Department of Orthopedics, Shanghai Tenth People's Hospital, Tongji University School of Medicine, \\ Shanghai, dDepartment of Nuclear Medicine, Changhai Hospital, The Second Military Medical

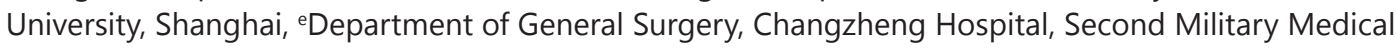 \\ University, Shanghai, China
}

\section{Key Words}

Anaplastic thyroid cancer $\bullet$ Sodium/iodide symporter $・$ P53 $•$ Radioiodine

\begin{abstract}
Aims: Anaplastic thyroid cancer(ATC) is one of the most aggressive solid tumors. Mutations in the p53 gene are common in anaplastic thyroid cancer, but the effects of p53 mutations are yet to be elucidated. Here, we investigated the role of p53 in ATC. Methods: p53 mutation was detect by immunohistochemistry in ATC tissues. Expression of NIS were measured using immunohistochemistry, qRT-PCR, western blot, immunofluorescence in ATC tissues and cell line 8505c. Luciferase reporter assay was performed to examine the effect of wild-type p53 on NIS. Radioiodide uptake assay and flow cytometry analysis were used to detect the role of wild-type p53 on radioiodide uptake.and cell apoptosis in ATC cell line. Results: We showed that the p53 mutation can be detected in ATC tissues. Furthermore, we demonstrated that wild-type p53 transactivated the NIS promoter. In 8505c cells transfected with wild-type p53, treatment with radioiodine resulted in increased radioiodine uptake and increased apoptotic cell death compared with $8505 \mathrm{c}$ cells harboring the p53 mutation. Conclusion: In summary, transfection with wild-type p53 can increase the therapeutic effect of radioiodine by regulating the expression of the NIS.

\section{Introduction}

Anaplastic thyroid cancer (ATC) is a rare subtype of thyroid cancer [1] but accounts for a significant proportion of thyroid cancer-related deaths, being one of the most lethal human neoplasms [2,3]. The lethality of ATC largely results from its resistance to L. Liu, D. Li and Z. Chen contributed equally to this work.

Xiaoping Zhang, Chengxiang Shan and Zhongwei Lv
Department of Nuclear Medicine, Shanghai Tenth People's Hospital, and Department of Institution of Interventional and Vascular Surgery, Tongji University, No. 301 Middle Yanchang Road, Shanghai, (China); E-Mail zxpsibs@163.com

\section{KARGER}


conventional therapies, such as radiation and targeted drug therapy. Iodine-131 $\left(^{131} \mathrm{I}\right)$, also known as radioiodine, treatment is one of the most effective methods for diagnosing and treating metastatic well-differentiated thyroid cancer. Because of the carcinogenicity of its beta radiation, the purely gamma-emitting radioiodine iodine-123 or the longer half-lived iodine-125 are now more frequently used for thyroid-related diagnostic and therapeutic applications. However, studies have shown that ATC and other poorly differentiated tumors have an impaired ability to concentrate radioiodine [4]. The loss of iodine uptake capacity results largely from reduced expression of the sodium/iodide symporter (NIS), a glycoprotein expressed on the plasma membrane that mediates iodide uptake in thyrocytes and is essential for the biosynthesis of the thyroid hormones thyroxine and triiodothyronine [5]. In non-thyroid tumors, in which NIS expression is generally low, the NIS is predominantly expressed in the cytoplasm. However, in thyroid tumors, shuttling of the NIS occurs between the cytoplasm and the plasma membrane [6]. NIS expression is driven by several thyroid specific transcription factors, such as Pax8 $[7,8]$, and nonspecific regulators, such as Nkx2.5 [9]. Furthermore, translocation of the NIS to the plasma membrane is also driven by several regulatory factors [10]. A recent study reported that transforming growth factor- $\beta 1$, a potent inhibitor of NIS transcription in normal thyroid cells, is upregulated by FoxP3 in thyroid cancer cells [11]. Regulation of the NIS is therefore complex and suppression of NIS expression during carcinogenesis is potentially mediated by multiple mechanisms.

The tumor suppressor p53 plays a vital role in genome stability and p53 activation is a primary mechanism underlying pathological responses to DNA damaging agents such as chemotherapy and radiotherapy $[12,13]$. The proteins encoded by the TP53 gene bind to DNA, regulating gene expression and preventing genome mutation. Mutations within this gene therefore increase the likelihood of uncontrolled cell division. This is exemplified by the finding that more than 50 percent of human tumors contain a mutation or deletion of the TP53 gene $[14,15]$, and mutations in the $p 53$ gene are a feature of poorly differentiated or undifferentiated thyroid carcinomas [16-21].

In this study, we compared ATC tissue specimens and an ATC cell line (8505c) with normal thyroid tissue and cells in terms of the frequency of p53 mutations and the expression of the NIS. 8505c cells are a widely used cell line that represent poorly differentiated thyroid tumors, displaying an impaired ability to concentrate radioiodine. Iodide uptake is a fundamental requisite for a radioiodine-based therapeutic approach to treat thyroid cancer. The relationship between p53 and the NIS was investigated in $8505 \mathrm{c}$ cells by transfection with wild-type p53 and the therapeutic effects of radioiodine were analyzed. By recovering the ability of thyroid cancer cells to concentrate radioiodine, the aim is to achieve effective radioiodine therapy of otherwise refractory tumors.

\section{Materials and Methods}

Tissue specimens and cell culture

In total, 51 anaplastic (undifferentiated) thyroid cancer tissue specimens and 47 normal thyroid tissue specimens were obtained from Chinese patients at Shanghai Tenth People's Hospital between 2012 and 2015. All human specimens were approved by the Research Ethics Committee of Shanghai Tenth People's Hospital (Shanghai, China).

The normal thyroid cell line FRTL-5 and the p53-mutated ATC cell line 8505c were used in this study . Both cell lines were cultured in RPMI 1640 medium supplemented with $5 \%$ fetal bovine serum at $37^{\circ} \mathrm{C}$ in a humidified atmosphere with $5 \% \mathrm{CO}_{2}$. Unless otherwise indicated, the TSH concentration was $1 \mathrm{mU} / \mathrm{ml}$.

\section{Cell line authentication}

Total genomic DNA was extracted from all cell lines using a DNeasy Tissue kit (Qiagen, Hilden, Germany) according to the manufacturer's protocols. The AmpFeSTR $\AA$ COfiler $\AA$ PCR Amplification kit (Applied Biosystems, Foster City, CA, USA) was used for short tandem repeat (STR) profiling. PCR amplification was performed on a GeneAmp 9700 or Veriti thermal cycler (Applied Biosystems). The PCR products were 


\section{Cellular Physiology Cell Physiol Biochem 2017;43:905-914

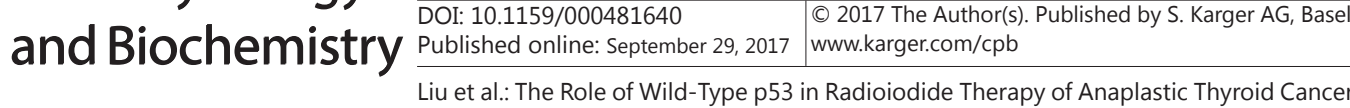

analyzed using an ABI 3130 genetic analyzer. STR profiles were analyzed using GeneMapper ID-X v1.1 Software (Applied Biosystems). The profiles were compared with official entries of different cell lines in the STR profile database maintained by the Japanese Collection of Research Bioresource (JCRB), the European Collection of Animal Cell Cultures (ECACC), the American Type Culture Collection (ATCC) or the Deutsche Sammlung von Mikroorganismen und Zellkulturen (DSMZ).

\section{Immunohistochemistry (IHC)}

Mutant p53 proteins have a longer half-life than wild-type p53 and therefore accumulate in the nucleus and can be detected by IHC [22]. The p53 mutation was detected by IHC using the SP kit (Thermo Fisher Scientific, Rockford, IL, USA) and a p53 monoclonal antibody (1:50; DAKO, Glostrup, Denmark). PBS was used as a negative control. The results were evaluated independently by three observers using a BH-2 optical microscope (Olympus Corporation, Tokyo, Japan) at 400× magnification. One hundred cells in each of 10 random visual fields were evaluated per slide and p53 was considered positive when more than $10 \%$ of the tumor cell nuclei showed strong staining (dark brown), as described previously [23].

\section{RNA extraction, reverse transcription and real-time PCR}

Total RNA was extracted using TRIzol reagent (TaKaRa Bio, Shiga, Japan). cDNA was synthesized using a cDNA synthesis kit according to the manufacturer's instructions (Toyobo, Osaka, Japan), and quantified by real-time PCR on an ABI 7500 FAST system (Applied Biosystems). The reaction mix was set up using the KOD SYBR Green qPCR kit (Toyobo) and primers: NIS, 5'-GCGTGGCTCTCTCAGTCAA3' (F) and 5'-GCGTCCATTCCTGAGCTG-3' (R), GAPDH, 5'-ACCACAGTCCATGCCATC AC-3'(F), and 5'TCCACCACCCTGTTGCTGTA-3'(R), were obtained from Sangon Biotech (Shanghai, China). Cycling conditions were as follows: $98^{\circ} \mathrm{C}$ for $2 \mathrm{~min}$, followed by 40 cycles of $98^{\circ} \mathrm{C}$ for $10 \mathrm{~s}, 60^{\circ} \mathrm{C}$ for $10 \mathrm{~s}$, and $68^{\circ} \mathrm{C}$ for $30 \mathrm{~s}$. Relative expression was measured in triplicate and normalized to GAPDH. Data were analyzed using the $2^{-\Delta \Delta \mathrm{CT}}$ method [24]. All primer sequences were validated for amplification efficiency by comparison with a genomic DNA standard curve and amplified single targets as determined by melting curve analysis. the amplification efficiency of the primers used to study NIS and GAPDH expression are 0.927 and 0.952.

\section{Western blot analysis}

Total and plasma membrane proteins were extracted using a protein extraction kit (BestBio, Shanghai, China), according to the manufacturer's instructions. Western blotting was performed using standard protocols and anti-NIS antibody (1:100; ab101084, Abcam), anti- $\beta$-actin antibody (ab8226, Abcam), antiBax antibody (ab77566, Abcam), anti-caspase-3 antibody (ab13847, Abcam), anti-bcl-2 antibody (ab692, Abcam), After incubation with the secondary antibody, immune complexes were detected using an eECL western blot kit (Thermo Fisher Scientific).

Cell transfection and luciferase promoter reporter assay [25]

Cell transfections with the indicated luciferase reporter, expression vectors encoding wild-type p53 or NIS and Renilla luciferase pRL null vector were performed using TransIT-TKO and TransIT-LT1 reagents from Mirus (Mirus Bio LLC, Madison, WI, USA). Cells were transiently transfected with either the wild-type p53-containing expression vector or the Renilla luciferase pRL null vector (pRL-CMV; Promega, Madison, WI, USA), used to correct for transfection efficiency. After $48 \mathrm{~h}$, cell lysates were assayed for luciferase activity using the dual-luciferase assay system (Promega, Fitchburg, WI, USA).

\section{Immunofluorescence}

After using STR profiling to confirm that our cell line were of ATC origin (Table 1), immunofluorescence analysis was preformed according to a previously published method [26]. Briefly, the tissue or cells were fixed in 4\% paraformaldehyde in PBS for 10 min, and then incubated with blocking buffer (PBS $1 \times+$ BSA 1\%) for 15 min after three 5-min washes in PBS. Immunostaining was performed using a rabbit polyclonal anti h-NIS antibody (1:600 dilution) [27] for $1 \mathrm{~h}$. After three 5-min washes in PBS, the cells were incubated with secondary antibody conjugated with FITC (1:160 dilution; Sigma-Aldrich, St. Louis, MO, USA) for 30 min, rewashed in PBS and incubated with Hoechst for $3 \mathrm{~min}$. After three final PBS washes, the cells were mounted with Vectashield (Vector Laboratories, Burlingame, CA, USA) and analyzed by fluorescent microscopy at a magnification of $400 \times$. 


\section{Radioiodide uptake assay}

Uptake of ${ }^{125}$ I was measured as previously described [28]. Briefly, cells were seeded into 12-well plates and the culture medium was aspirated. The cells were then washed with $1 \mathrm{ml}$ of Hank's balanced salt solution (Life Technologies, Gaithersberg, MD, USA) supplemented with HEPES 10 mM, pH 7.3. To initiate ${ }^{125} \mathrm{I}$ uptake, $500 \mu \mathrm{l}$ of buffered HBSS containing $0.1 \mu \mathrm{Ci}$ carrier-free $\mathrm{Na}^{125} \mathrm{I}$ and $10 \mathrm{mM} \mathrm{NaI}$ was added to each well to obtain a specific activity of $20 \mathrm{mCi} / \mathrm{mmol}$.

\section{Apoptosis Flow Cytometry Analysis}

Annexin V-FITC and propidium iodide flow cytometry using ApoAlert Annexin V kit (Clontech, Mountain View, CA) were used to assess the effects of cell apoptosis. Cells were harvested and stained with Annexin V-FITC and propidium iodide according to the manufacturer's protocol. Cell samples were analyzed on a FACSCalibur and apoptotic fractions were determined.

\section{Statistical analysis}

Data are expressed as the mean \pm SD of values obtained from at least three independent experiments. Statistical analysis was performed using t-test and the one-factor ANOVA. $\mathrm{P}<0.05$ were considered statistically significant.

\section{Results}

Increased detection of the p53 mutation and decreased NIS expression in ATC tissue and cells

To detect the p53 mutation in ATC tissue, IHC was performed using an anti-p53 monoclonal antibody. According to a previously published method [23], one hundred cells in each of 10 random visual fields were evaluated per slide and p53 was considered positive when more than $10 \%$ of the tumor cell nuclei showed strong staining (dark brown) (Fig. 1A). In total, $56.86 \%(29 / 51)$ of the ATC tissue specimens were positive for the p53 mutation, compared with $4.26 \%(2 / 47)$ of the normal thyroid tissue specimens. IHC staining using an NIS monoclonal antibody [29] showed a significant reduced NIS protein level in the ATC

Fig. 1. Detection of the p53 mutation and NIS expression analysis in anaplastic thyroid cancer tissue. (A) IHC was performed on anaplastic thyroid cancer tissue specimens using an anti-p53 and NIS monoclonal antibody. Dark brown staining of cell nuclei indicates the presence of the p53 mutation. (B) Expression levels of NIS mRNA in normal thyroid tissue and wt p53,mt p53 anaplastic thyroid cancer tissue, as determined by qRTPCR and presented as a box plot. GAPDH was included as an endogenous control. Data are expressed as the mean \pm

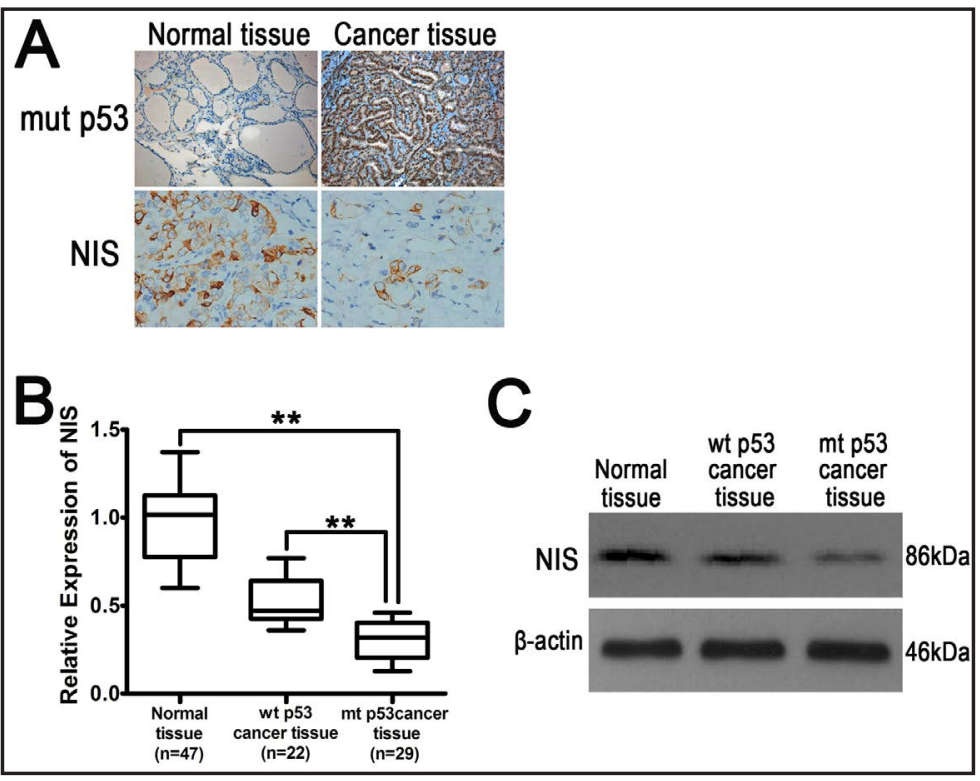
SD of values obtained from at least three independent experiments. (C) Expression levels of NIS protein in normal thyroid tissue and anaplastic thyroid cancer tissue determined by western blot analysis. $\beta$-actin was included as a loading control. ${ }^{* *} \mathrm{p}<0.01$. 
Fig. 2. NIS expression analysis in a p53-mutated anaplastic thyroid cancer (8505c) cell line. (A) Expression levels of NIS mRNA in normal thyroid cells and a p53-mutated anaplastic thyroid cancer (8505c) cell line, as determined by qRT-PCR. GAPDH was included as an endogenous control. Data are expressed as the mean \pm SD of values obtained from at least three independent experiments. (B) Expression levels of NIS protein in normal thyroid cells and

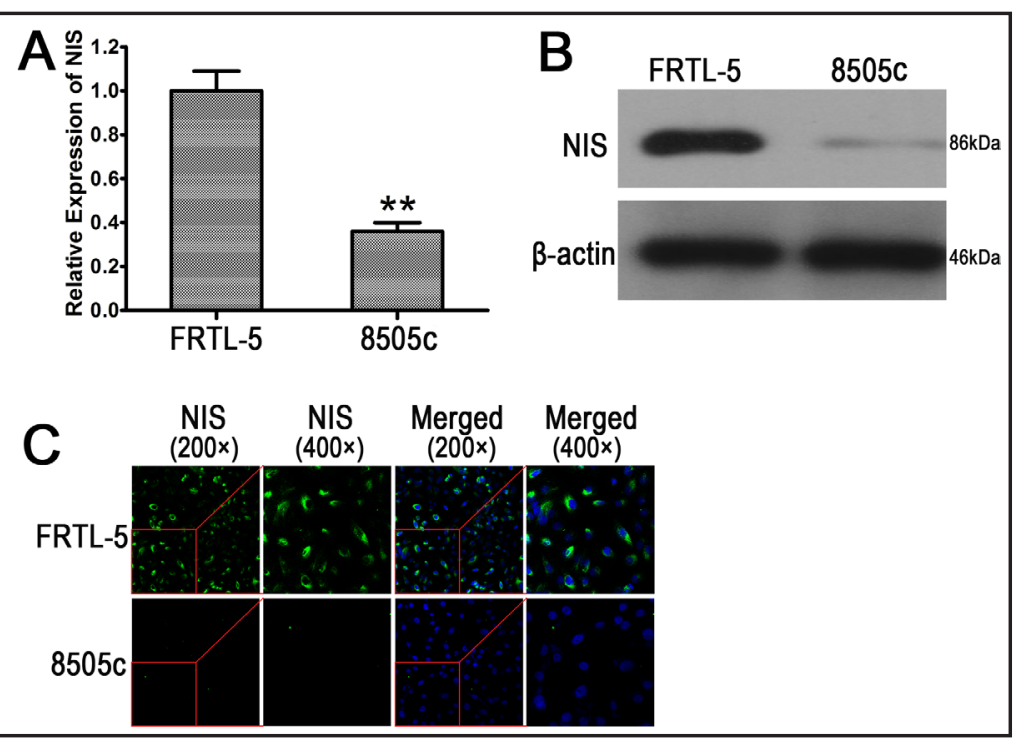
$8505 \mathrm{c}$ cells, as determined by western blot analysis. $\beta$-actin was included as a loading control. (C) Immunofluorescent localization of NIS in normal thyroid cells and 8505c cells. (left) NIS (green) localization; (right) Double immunofluorescence: NIS (green) and DAPI nuclear staining (blue). ${ }^{* *} \mathrm{p}<0$.

Table 1. Short tandam repeated (STR) sequencing results ATC cell lines

\begin{tabular}{lccccccccc}
\hline Cell line & Amelogenin & D13S317 & D5S818 & D7S820 & Vwa & CSF1P0 & D16S539 & TH01 & TP0X \\
\hline $8505 \mathrm{c}$ & $\mathrm{X}$ & 13 & 10,11 & 10 & 17,19 & 12,13 & 12 & 6,9 & 11 \\
\hline
\end{tabular}

tissue specimens (Fig. 1A). The NIS mRNA and protein expression levels, determined by qRT-PCR and western blot analysis, respectively, were both downregulated in positive p53 mutation ATC tissue compared with normal thyroid tissue and negative p53 mutation ATC tissue ( $p<0.01$; Fig. 1B, C). Similar result concerning NIS mRNA and protein expression levels was found in a p53-mutated ATC cell line (8505c) compared with normal thyroid cells FRTL5 ( $p<0.01$, Fig. $2 A$ and $B$, respectively). Immunofluorescence analysis indicated that both total NIS protein and membrane-expressed NIS protein were significantly downregulated in $8505 \mathrm{c}$ cells compared with normal thyroid cells (Fig. 2C). Taken together, these findings indicate that detection of the p53 mutation is increased and NIS expression is decreased in ATC tissue and cells.

\section{Wild-type p53 induces NIS expression in ATC cells}

After using STR profiling to confirm that our cell lines were of ATC origin (Table 1), we investigated the relationship between NIS and p53. 8505c cells were transfected with a wildtype-p53 expression vector or control vector followed by qRT-PCR and western blot analysis. The mRNA and protein expression levels of NIS were significantly increased in wild-type p53 transfected $8505 \mathrm{c}$ cells ( $\mathrm{p}<0.01$; Fig. $3 \mathrm{~A}$ and $\mathrm{B}$, respectively). To investigate the relationship between NIS expression and the p53 mutation further, immunofluorescence analysis was performed to detect the expression of NIS in 8505c transfectants. As shown in Fig. 3C, both total NIS protein and membrane-expressed NIS protein were significantly upregulated in 8505c cells transfected with wild-type p53.

Previous studies have shown that NIS expression is regulated by several transcription regulators [30], we examined whether wild-type p53 upregulates NIS expression through binding to NIS promoter in ATC cells. The ability of wild-type p53 to regulate NIS promoter activity was investigated by a luciferase promoter reporter assay. Luciferase activity was significantly increased when $8505 \mathrm{c}$ cells were co-transfected with the wild-type p53

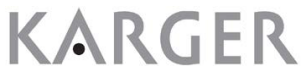




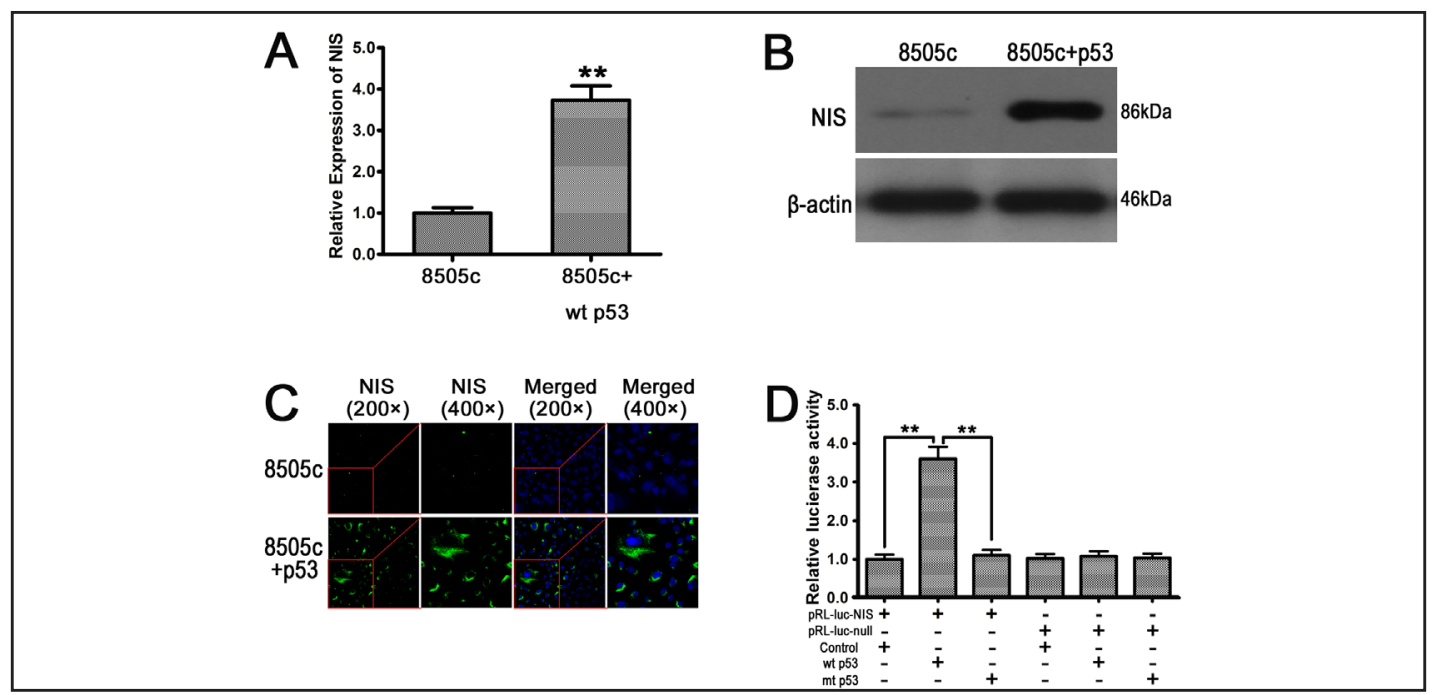

Fig. 3. Wild-type p53 transactivates the promoter of NIS. (A) mRNA levels of NIS in 8505c cells transfected with wild-type p53 or control vector, as determined by qRT-PCR. GAPDH was included as an endogenous control. (B) Protein expression of NIS in 8505c cells transfected with wild-type p53 or control vector, as determined by western blotting. $\beta$-actin was included as a loading control. (C) Immunofluorescent localization of NIS in 8505c cells transfected with wild-type p53 or control vector. (left panels) NIS (green) localization; (right panels) double immunofluorescence: NIS (green) and DAPI nuclear staining (blue). Magnification: $200 \times$. (D) $8505 \mathrm{c}$ cells were co-transfected with the NIS promoter luciferase reporter and wild-type p53 expression vectors. Luciferase activity was assayed $24 \mathrm{~h}$ after transfection and expressed as fold induction relative to the control after normalization for transfection efficiency using the dual-luciferase assay system. Histograms show the means of at least three experiments performed in quadruplicate. Bars indicate the S.D.

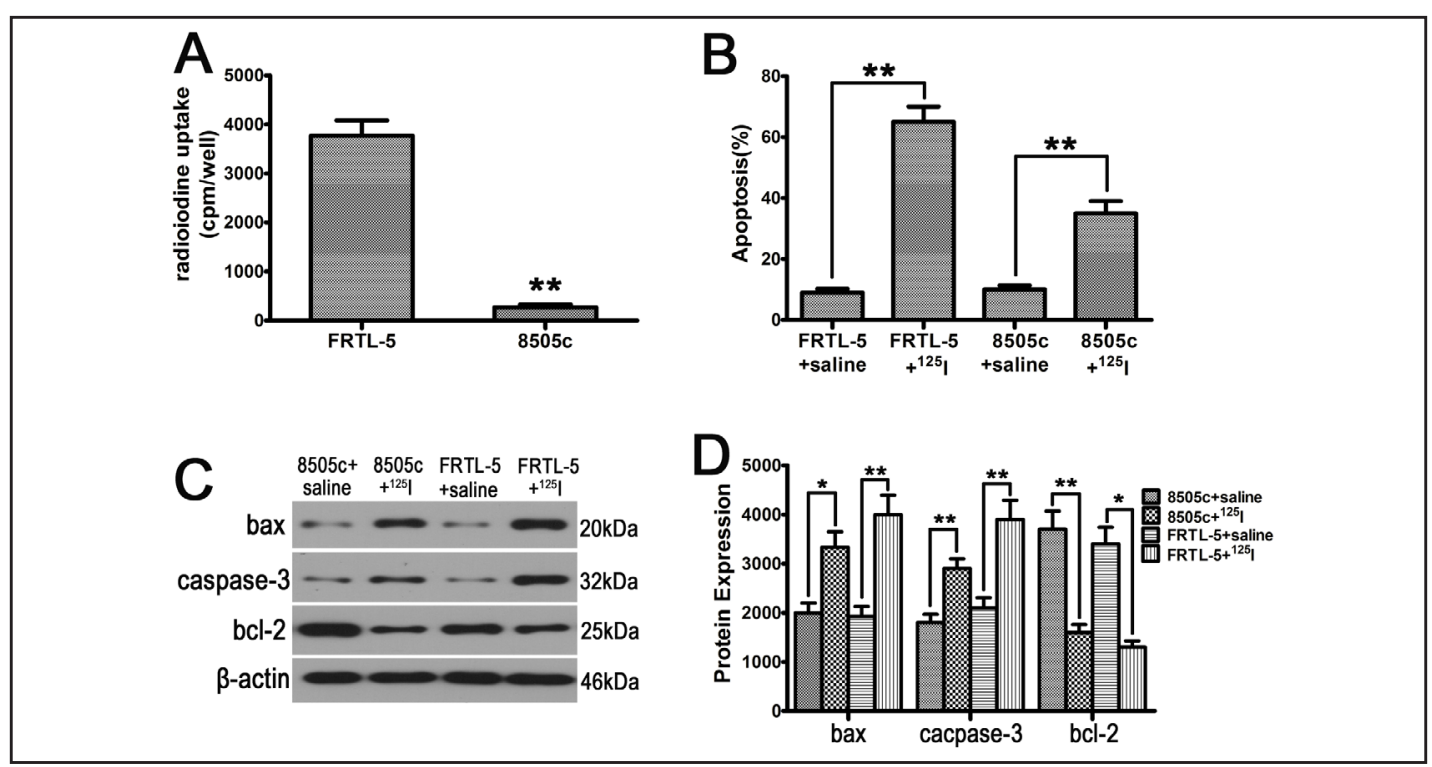

Fig. 4. Radioiodine uptake induced apoptosis in normal thyroid FRTL-5 cells and thyroid cancer 8505c cells. (A) Radioiodine uptake (cpm/well) in normal thyroid FRTL-5 cells and thyroid cancer 8505c cells. (B) Apoptosis (\%), as determined by flow cytometry, in FRTL-5 and $8505 \mathrm{c}$ cells treated with ${ }^{125}$ I or saline as a control. (C,D) Western blot analysis of the expression of pro-apoptotic proteins Bax and Caspase-3 and anti-apoptotic protein Bcl-2 in FRTL-5 and $8505 \mathrm{c}$ cells treated with ${ }^{125} \mathrm{I}$ or saline as a control. The western blot image (C) and the densitometric analysis data (D) are shown. $\beta$-actin was included as a loading control. 


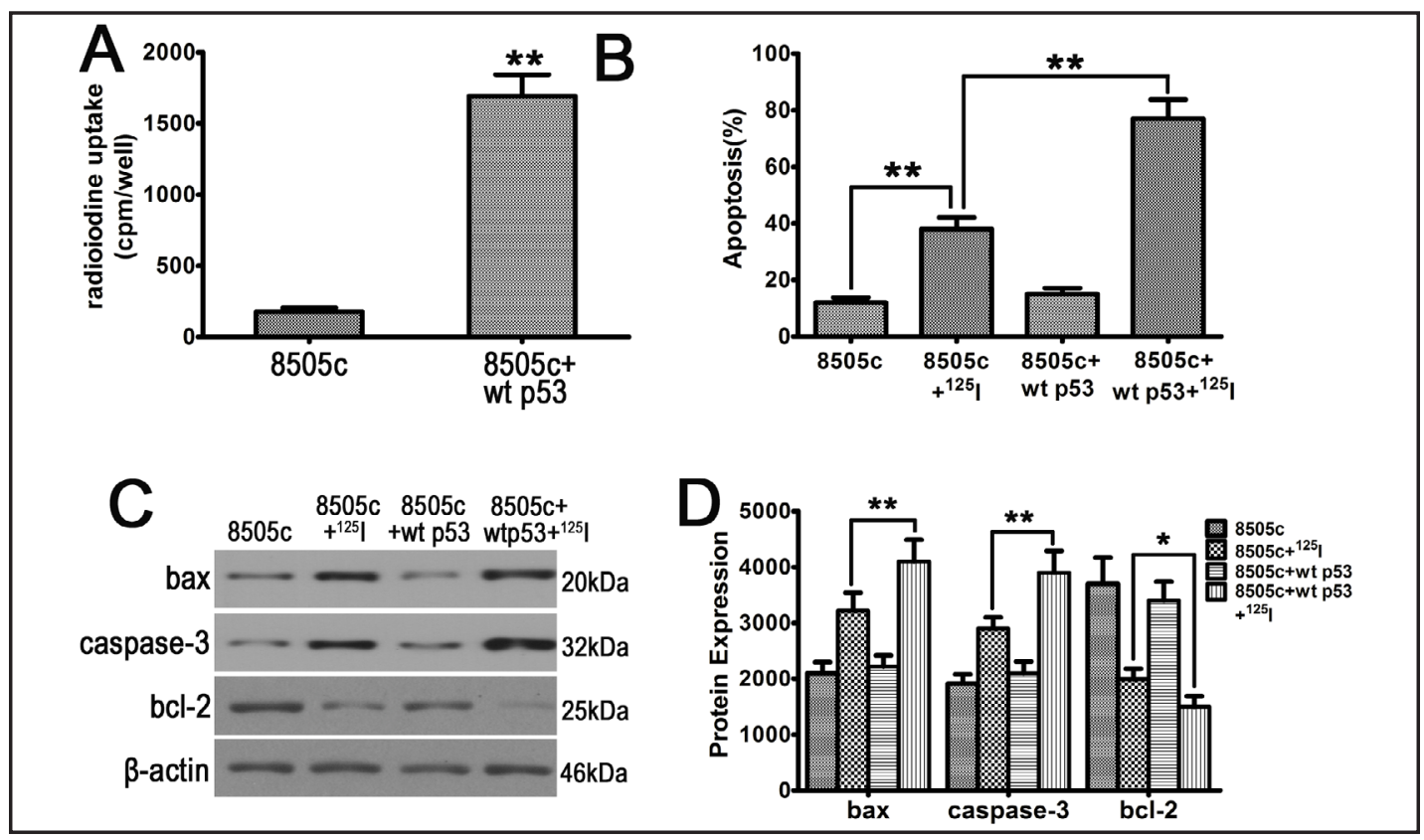

Fig. 5. Wild-type p53 increases radioiodine uptake and induces apoptosis in anaplastic thyroid cancer. (A) Radioiodine uptake (cpm/well) in thyroid cancer 8505c cells transfected with wild-type p53 or control vector. (B) Apoptosis (\%), as determined by flow cytometry, in 8505 c cells treated with or without ${ }^{125}$ I, and transfected with wild-type p53 or control vector. (C,D) Western blot analysis of the expression of proapoptotic proteins Bax and Caspase- 3 and anti-apoptotic protein Bcl-2 in 8505c cells treated with or without ${ }^{125} \mathrm{I}$, and transfected with wild-type p53 or control vector. The western blot image (C) and the densitometric analysis data (D) are shown. $\beta$-actin was included as a loading control.

expression plasmid and the NIS promoter luciferase reporter plasmid (Fig. 3D). Taken together, these findings confirmed that wild-type p53 transactivates the promoter of NIS.

${ }^{125}$ I treatment induced apoptosis in normal thyroid FRTL-5 cells and anaplastic thyroid 8505 c cancer cells

To investigate whether decreased expression of NIS correlates with impaired iodine uptake in thyroid cells, cells were treated with ${ }^{125} \mathrm{I}$ and the uptake of radioiodine was assessed. Radioiodine uptake was found to be significantly reduced in $8505 \mathrm{c}$ cells compared with FRTL-5 cells $(\mathrm{p}<0.01$; Fig. $4 \mathrm{~A}$ ). Next, the effect of radioiodine on cell apoptosis was investigated by flow cytometry. ${ }^{125}$ I was found to induce apoptosis in both cell types (Fig. 4B). However, the percentage of apoptosis was significantly reduced in $8505 \mathrm{c}$ cells $(34.1 \%)$ treated with ${ }^{125}$ I compared with ${ }^{125}$ I-treated FRTL-5 cells $(63.3 \%)(\mathrm{p}<0.01)$. To confirm these findings, western blot analysis was performed on ${ }^{125} \mathrm{I}$-treated and untreated cells to assess the expression of pro- and anti-apoptotic proteins (Fig. 4C, D). The expression of pro-apoptotic proteins Bax and caspase- 3 was decreased, whereas the expression of anti-apoptotic protein Bcl-2 was increased in ${ }^{125}$ I-treated $8505 \mathrm{c}$ cells compared with ${ }^{125}$ I-treated FRTL-5 cells. In summary, 8505c cells displayed reduced radioiodine uptake and cell apoptosis compared with normal thyroid cells under treatment with ${ }^{125}$ I, correlating with decreased expression of pro-apoptotic proteins and increased expression of anti-apoptotic proteins.

Transfection with wild-type p53 rescues radioiodine uptake and promotes apoptosis in ATC cells treated with ${ }^{125}$ I

To investigate whether wild-type p53 improves radioiodine uptake and promotes apoptosis in ATC cells treated with ${ }^{125}$ I, 8505c cells were transfected with wild-type-p53 or control vector were analyzed. Radioiodine uptake was significantly increased in $8505 \mathrm{c}$ cells transfected with wild-type p53 (Fig. 5A). Furthermore, ${ }^{125}$ I treatment induced cell apoptosis 
was further increased in wild-type p53 transfected 8505c cells (Fig. 5B). This result was confirmed by western blot analysis of pro- and anti-apoptotic proteins. Expression of the pro-apoptotic proteins Bax and caspase- 3 was further upregulated, whereas anti-apoptotic protein Bcl-2 was further downregulated in ${ }^{125}$ I-treated $8505 \mathrm{c}$ cells transfected with wildtype p53 (Fig. 5C, D). Taken together, these findings indicate that wild-type p53 transfection restores radioiodine uptake and promotes apoptosis in ATC cells treated with ${ }^{125} \mathrm{I}$, a promising result in terms of anti-cancer therapy.

\section{Discussion}

The NIS-mediated ability of thyroid cancer cells to concentrate iodide is exploited for the purposes of diagnostic imaging and radioiodine therapy [31, 32]. However, ATC, a rare subtype of poorly differentiated thyroid tumor, is refractory to radioiodine therapy. The loss of iodine uptake capacity in non-differentiated cancers results from suppression of NIS expression [4]. By contrast, NIS expression has been found to be upregulated in a range of cancers including breast and liver. In these non-thyroid cancers, NIS is retained intracellularly and in some cases is reported to play a role in cell migration and invasion during carcinogenesis rather than iodide uptake [33-36]. Previous studies have shown that defects in NIS function usually occur at the gene expression level [6]. Various factors have been identified to be involved in the transcriptional regulation of NIS expression. In thyroid cancers, NIS expression is mainly controlled by the transcription factors Pax-8 and Nkx2.1, which target the upstream enhancer (NUE), and by the cardiac homeobox transcription factor Nkx2.5, which regulates the activity of the NIS core promoter [9, 37-39]. Recently, in liver cancer cells, p53 was shown to mediate transcriptional activation of the NIS in response to DNA damage, triggering DNA damage-induced apoptosis [30]. Previous studies have shown that a higher frequency of mutations in p53 in ATC [40] and p53 plays an important role in developing ATC [41]. A correlation between p53 suppression, a lack of differentiation markers including NIS, and poor patient prognosis has previously been noted $[19,42]$, however, studies confirming that NIS is a target gene for p53-family members in thyroid cancer cells was lacking.

Here, we present evidence that 8505 c cells transfection with wild-type p53 transactivates the NIS promoter, increasing endogenous NIS expression and targeting this glycoprotein to the plasma membrane. Accumulation of NIS in wild-type p53-transfected cells resulted in increased radioiodine uptake and increased cell apoptosis following treatment with ${ }^{125}$. The role of NIS accumulation in cell apoptosis was confirmed previous findings [30]. The regulation of the NIS by p53 indicates the potential therapeutic benefit in restoring the radioiodine uptake ability of poorly differentiated thyroid cancer cells. Further studies are now required to determine whether p53 alone or in combination with other regulatory factors could be employed to enhance radioiodine uptake by thyrocytes, potentially increasing the responsiveness of patients with ATC to radioiodine therapy.

\section{Acknowledgements}

This work was funded by the National Natural Science Foundation of China (81572626, 81302332, 81371595, 81501505 and 81300723).

All procedures performed in studies involving human participants were in accordance with the ethical standards of the institutional research committee and with the 1964 Helsinki declaration and its later amendments or comparable ethical standards.

Informed consent Informed consent was obtained from all individual participants included in the study.

\section{Disclosure Statement}

All the authors state that they have no conflicts of interest. 


\section{Cellular Physiology Cell Physiol Biochem 2017;43:905-914 \begin{tabular}{ll|l} 
and Biochemistry & Dublished onlIne: September 29, 2017 & $\begin{array}{l}\text { C } 2017 \text { The Author(s). Published by S. Karger AG, Basel } \\
\text { www.karger.com/cpb }\end{array}$ \\
\hline
\end{tabular}}

Liu et al.: The Role of Wild-Type 533 in Radioiodide Therapy of Anaplastic Thyroid Cancer

\section{References}

1 Wynford-Thomas D: Origin and progression of thyroid epithelial tumours: cellular and molecular mechanisms. Horm Res 1997;47:145-157.

-2 Schlumberger MJ: Papillary and follicular thyroid carcinoma. N Engl J Med 1998;338:297-306.

3 Sherman SI: Thyroid carcinoma. Lancet 2003;361:501-511.

-4 Wapnir IL, Van dRM, Nowels K, Amenta PS, Walton K, Montgomery K, Greco RS, Dohán O, Carrasco N: Immunohistochemical profile of the sodium/iodide symporter in thyroid, breast, and other carcinomas using high density tissue microarrays and conventional sections. J Clin Endocrinol Metab 2003;88:18801888.

-5 Dai G, Levy 0, Carrasco N: Cloning and characterization of the thyroid iodide transporter. Nature 1996;379:458-460.

-6 Dohán O, De IVA, Paroder V, Riedel C, Artani M, Reed M, Ginter CS, Carrasco N: The Sodium/Iodide Symporter (NIS): Characterization Regulation and Medical Significance. Endocr Rev 2003;24:48-77.

7 Nicola JP, Nazar MMascanfroni ID, Pellizas CG, Masini Repiso AM: NF-kappaB p65 subunit mediates lipopolysaccharide-induced $\mathrm{Na}(+) / \mathrm{I}(-)$ symporter gene expression by involving functional interaction with the paired domain transcription factor Pax8. Mol Endocrinol 2013;24:1846-1862.

-8 Ohno M, Zannini M, Levy O, Carrasco N, Lauro RD: The Paired-Domain Transcription Factor Pax8 Binds to the Upstream Enhancer of the Rat Sodium/Iodide Symporter Gene and Participates in Both ThyroidSpecific and Cyclic-AMP-Dependent Transcription. Mol Cell Biol 1999;19:2051--2060.

-9 Dentice M, Luongo C, Elefante A, Romino R, Ambrosio R, Vitale M, Rossi G, Fenzi G, Salvatore D: Transcription factor Nkx-2.5 induces sodium/iodide symporter gene expression and participates in retinoic acid- and lactation-induced transcription in mammary cells. Mol Cell Biol 2004;24:7863-7877.

10 Taki K, Kogai T, Kanamoto Y, Hershman JM, Brent GA: A thyroid-specific far-upstream enhancer in the human sodium/iodide symporter gene requires Pax-8 binding and cyclic adenosine 3',5'-monophosphate response element-like sequence binding proteins for full activity and is differentially regulated in normal and thyroid cancer cells. Mol Endocrinol 2002;16:2266-2282.

11 Ma S, Wang Q, Ma X, Wu L, Guo F, Ji H, Liu F, Zhao Y, Qin G: FoxP3 in papillary thyroid carcinoma induces NIS repression through activation of the TGF-beta1/Smad signaling pathway. Tumour Biol 2016;37:989-998.

12 Liang L, Zhang Z: Gambogic Acid Inhibits Malignant Melanoma Cell Proliferation Through Mitochondrial p66shc/ROS-p53/Bax-Mediated Apoptosis. Cell Physiol Biochem 2016;38:1618-1630.

13 Bose D, Banerjee S, Das S, Chatterjee N, Saha KD: Heat Killed Attenuated Leishmania Induces Apoptosis of HepG2 Cells Through ROS Mediated p53 Dependent Mitochondrial Pathway. Cell Physiol Biochem 2016;38:1303-1318.

14 Hollstein M, Sidransky D, Vogelstein B, Harris CC: p53 mutations in human cancers. Science 1991;253:4953.

15 Tian X, Dai S, Sun J, Jiang S, Sui C, Meng F, Li Y, Fu L, Jiang T, Wang Y, Su J, Jiang Y: Inhibition of MDM2 Re-Sensitizes Rapamycin Resistant Renal Cancer Cells via the Activation of p53. Cell Physiol Biochem 2016;39:2088-2098.

16 Ito T, Seyama T, Mizuno T, Tsuyama N, Hayashi T, Hayashi Y, Dohi K, Nakamura N, Akiyama M: Unique association of p53 mutations with undifferentiated but not with differentiated carcinomas of the thyroid gland. Cancer Res 1992;52:1369-1371.

$>17$ Fagin JA, Matsuo K, Karmakar A, Chen DL, Tang SH, Koeffler HP: High prevalence of mutations of the p53 gene in poorly differentiated human thyroid carcinomas. J Clin Invest 1993;91:179-184.

18 Dobashi Y, Sakamoto A, Sugimura H, Mernyei M, Mori M, Oyama T, Machinami R: Overexpression of p53 as a possible prognostic factor in human thyroid carcinoma. Am J Surg Pathol 1993;17:375-381.

19 Donghi R, Longoni A, Pilotti S, Michieli P, Della Porta G, Pierotti MA: Gene p53 mutations are restricted to poorly differentiated and undifferentiated carcinomas of the thyroid gland. J Clin Invest 1993;91:17531760.

20 Matias-Guiu X, Cuatrecasas M, Musulen E, Prat J: p53 expression in anaplastic carcinomas arising from thyroid papillary carcinomas. J Clin Pathol 1994;47:337-339.

21 Fusco A SM: Human thyroid carcinogenesis. Forum 1997 7:214-229.

22 Hall PA, Ray A, Lemoine NR, Midgley CA, Krausz T, Lane DP: p53 immunostaining as a marker of malignant disease in diagnostic cytopathology. Lancet 1991;338:513. 


\section{Cellular Physiology Cell Physiol Biochem 2017;43:905-914 \begin{tabular}{l|l|l|l|} 
DOI: 10.1159/000481640 & $\begin{array}{l}\text { C } 2017 \text { The Author(s). Published by S. Karger AG, Basel } \\
\text { www.karger.com/cpb }\end{array}$
\end{tabular}

-23 Munger K, Baldwin A, Edwards KM, Hayakawa H, Nguyen CL, Owens M, Grace M, Huh K: Mechanisms of human papillomavirus-induced oncogenesis. J Virol 2004;78:11451-11460.

24 Schmittgen TD, Livak KJ: Analyzing real-time PCR data by the comparative C(T) method. Nat Protoc 2008;3:1101-1108.

25 Guerrieri F, Piconese S, Lacoste C, Schinzari V, Testoni B, Valogne Y, Gerbal-Chaloin S, Samuel D, Brechot C, Faivre J, Levrero M: The sodium/iodide symporter NIS is a transcriptional target of the p53-family members in liver cancer cells. Cell Death Dis 2013;4:e807.

-26 Presta I, Arturi F, Ferretti E, Mattei T, Scarpelli D, Tosi E, Scipioni A, Celano M, Gulino A, Filetti S, Russo D: Recovery of NIS expression in thyroid cancer cells by overexpression of Pax8 gene. BMC Cancer 2005;5:80.

-27 Arturi F, Russo D, Bidart JM, Scarpelli D, Schlumberger M, Filetti S: Expression pattern of the pendrin and sodium/iodide symporter genes in human thyroid carcinoma cell lines and human thyroid tumors. Eur J Endocrinol 2001;145:129-135.

28 Weiss SJ, Philp NJ, Grollman EF: Iodide transport in a continuous line of cultured cells from rat thyroid. Endocrinology 1984;114:1090-1098.

29 Abdulrahman RM, Boon MR, Sips HC, Guigas B, Rensen PC, Smit JW, Hovens GC: Impact of Metformin and compound C on NIS expression and iodine uptake in vitro and in vivo: a role for CRE in AMPK modulation of thyroid function. Thyroid 2014;24:78-87.

30 Guerrieri F, Piconese S, Lacoste C, Schinzari V, Testoni B, Valogne Y, Gerbal-Chaloin S, Samuel D, Bréchot C, Faivre J: The sodium/iodide symporter NIS is a transcriptional target of the p53-family members in liver cancer cells. Cell Death Dis 2012;4:e807.

-31 Hingorani M, Spitzweg C, Vassaux G, Newbold K, Melcher A, Pandha H, Vile R, Harrington K: The biology of the sodium iodide symporter and its potential for targeted gene delivery. Curr Cancer Drug Targets 2010;10:242-267.

-32 Mazzaferri EL, Kloos RT: Clinical review 128: Current approaches to primary therapy for papillary and follicular thyroid cancer. J Clin Endocrinol Metab 2001;86:1447-1463.

33 Moon DH, Lee SJ, Park KY, Park KK, Ahn SH, Pai MS, Chang H, Lee HK, Ahn IM: Correlation between 99m Tcpertechnetate uptakes and expressions of human sodium iodide symporter gene in breast tumor tissues. Nucl Med Biol 2001;28:829-834.

34 Cianfarani F, Baldini E, Cavalli A, Marchioni E, Lembo L, Teson M, Persechino S, Zambruno G, Ulisse S, Odorisio T: TSH Receptor and Thyroid-Specific Gene Expression in Human Skin. J Invest Dermatol 2010;130:93-101.

-35 Damle AA, Narkar AA, Badwe RA: Radioiodide uptake and sodium iodide symporter expression in breast carcinoma. Indian J Exp Biol 2011;49:416-422.

-36 Lacoste C, Herve J, Bou Nader M, Dos Santos A, Moniaux N, Valogne Y, Montjean R, Dorseuil O, Samuel D, Cassio D, Portulano C, Carrasco N, Brechot C, Faivre J: Iodide transporter NIS regulates cancer cell motility and invasiveness by interacting with the Rho guanine nucleotide exchange factor LARG. Cancer Res 2012;72:5505-5515.

-37 Kogai T, Brent GA: The sodium iodide symporter (NIS): regulation and approaches to targeting for cancer therapeutics. Pharmacol Ther 2012;135:355-370.

38 Kogai T, Taki K, Brent GA: Enhancement of sodium/iodide symporter expression in thyroid and breast cancer. Endocr Relat Cancer 2006;13:797-826.

39 De Felice M, Di Lauro R: Thyroid development and its disorders: genetics and molecular mechanisms. Endocr Rev 2004;25:722-746.

40 Landa I, Ibrahimpasic T, Boucai L, Sinha R, Knauf JA, Shah RH, Dogan S, Ricarte-Filho JC, Krishnamoorthy GP, Xu B, Schultz N, Berger MF, Sander C, Taylor BS, Ghossein R, Ganly I, Fagin JA: Genomic and transcriptomic hallmarks of poorly differentiated and anaplastic thyroid cancers. J Clin Invest 2016;126:1052-1066.

41 Moretti F, Farsetti A, Soddu S, Misiti S, Crescenzi M, Filetti S, Andreoli M, Sacchi A, Pontecorvi A: p53 reexpression inhibits proliferation and restores differentiation of human thyroid anaplastic carcinoma cells. Oncogene 1997;14:729-740.

42 Fagin JA, Tang SH, Zeki K, Di Lauro R, Fusco A, Gonsky R: Reexpression of thyroid peroxidase in a derivative of an undifferentiated thyroid carcinoma cell line by introduction of wild-type p53. Cancer Res 1996;56:765-771. 